\title{
Qualificação para as atividades do turismo: Perfil profissional de trabalhadores, proprietários e gestores de empresas de alimentação fora do lar na Região Litorânea Central do Estado de Santa Catarina (Brasil)
}

\section{Qualification for the tourism activities: Professional profile of employees, owners and managers of Food Service enterprises in Santa Catarina (Brazil) Central Coastal Region}

\author{
Fernando Goulart Rocha (ROCHA, F. G.) ${ }^{*}$ e \\ Fabiana Mortimer Amaral (AMARAL, F. M.) ${ }^{* *}$
}

\begin{abstract}
RESUMO - A pesquisa foi realizada entre novembro de 2008 e março de 2009 a fim de levantar o perfil profissional de trabalhadores, proprietários e gestores de estabelecimentos de alimentação fora do lar em municípios da Região Litorânea Central do Estado de Santa Catarina. Metodologia: A pesquisa foi realizada em sete municípios: Florianópolis, São José, Governador Celso Ramos, Biguaçu, Palhoça, Paulo Lopes e Garopaba. Foram respondidos 1.516 questionários: 1.110 por funcionários $(73,22 \%)$ e 406 por gestores ou proprietários $(26,78 \%)$. Resultados: Os resultados apontaram para a ampla demanda de trabalhadores que não possuíam certificação técnica para as atividades que estavam desempenhando. Em relação aos gestores e proprietários, percebeu-se, principalmente, a necessidade de investirem em formação profissional para as rotinas administravas que exerciam. Considerações Finais: Avaliaram-se como imprescindíveis programas de capacitação profissional para trabalhadores, gestores e proprietários envolvidos com o setor de alimentação fora do lar na área investigada. Por outro lado, é pertinente a concepção de indicadores que permitam levantar dados relacionados à qualidade dos serviços de alimentação oferecidos aos turistas e à população residente.
\end{abstract}

Palavras-chave: Alimentação fora do lar; Trabalhadores; Proprietários; Gestores.

\begin{abstract}
The survey was accomplished between November 2008 and March 2009 in order to bring up the professional profile of employees, owners and managers of Food Service enterprises in some cities of Santa Catarina State Central Coastal Region. Methodology: The survey was accomplished in seven cities: Florianópolis, São José, Governador Celso Ramos, Biguaçu, Palhoça, Paulo Lopes, and Garopaba. 1516 questionnaires were answered: $1110(73 \%)$ by employees and $406(27 \%)$ by owners and managers. Results: The results showed that a large number of employees did not have technical certification for the activities which they were performing. In relation to the managers and owners, it was noticed, mainly, the need of investment in professional training or graduation in administrative activities that they are working in their establishments. Conclusions: It is essential professional training programs for workers, managers, supervisors and owners involved in Food Service enterprises in the investigated area. On the other hand, it is pertinent the conception of indicators which allow collecting data related to the quality of Food Service offered to tourists and the resident population.
\end{abstract}

Key words: Food Services enterprises; Employees; Owners; Managers.

\footnotetext{
* Graduação, Mestrado e Doutorado em Geografia pela Universidade Federal de Santa Catarina (UFSC). Professor de Ciências Humanas do Instituto Federal de Santa Catarina (IFSC). Endereço para correspondência: Rua 14 de julho, 150, Enseada dos Marinheiros, Coqueiros. CEP: 88075-010 Florianópolis - SC. Telefone: 55 (48) 3271-1400. E-mail: fernandogr@ifsc.edu.br

** Graduação em Farmácia - Bioquímica Tecnologia de Alimentos, Mestrado em Química Orgânica e Doutorado em Química Analítica pela Universidade Federal de Santa Catarina (UFSC). Professora de Produção de Alimentos do Instituto Federal de Santa Catarina (IFSC). Endereço para correspondência: Rua 14 de julho, 150, Enseada dos Marinheiros, Coqueiros. CEP: 88075-010 - Florianópolis - SC. Telefone: 55 (48) 3271-1400. E-mail: fabiana@ifsc.edu.br
} 


\section{INTRODUÇÃO}

O turismo no litoral do Estado de Santa Catarina está vinculado aos atributos da paisagem natural associado à diversidade de praias, baías e enseadas, lagunas e lagoas costeiras de diferentes formas e tamanhos. Além disso, do ponto de vista econômico, a atividade está estreitamente vinculada aos arranjos socioeconômicos locais. (PEREIRA, 2003). Nesse sentido, a atual regionalização do turismo no Estado delimita a ocorrência de dez destinos indutores relacionados à combinação de elementos históricos, geográficos e culturais da paisagem catarinense. Entre os mencionados destinos turísticos, cinco deles estão localizados na porção litorânea, confirmando a posição de destaque ocupada pelo turismo, particularmente de sol e praia, nos municípios costeiros do Estado.

A capital de Santa Catarina e municípios adjacentes estão incluídos na região turística denominada Grande Florianópolis (SANTUR, 2012), coincidindo com a nomenclatura mesorregional adotada pelo Instituto Brasileiro de Geografia e Estatística (IBGE, 2012). Ambas as divisões incluem nesse domínio regional municípios costeiros (Governador Celso Ramos, Biguaçu, São José, Florianópolis e Palhoça), bem como não costeiros (Santo Amaro da Imperatriz, São Bonifácio, Anitápolis, Águas Mornas, Rancho Queimado, São Pedro de Alcântara, Antônio Carlos e Angelina).

A pesquisa aqui apresentada foi realizada apenas nos municípios da orla atlântica da Grande Florianópolis, além de Paulo Lopes e Garopaba, municípios ao sul dessa região e compreendidos no destino turístico conhecido como Encantos do Sul. Nessa direção, diante da delimitação geográfica adotada pela pesquisa e a fim de não causar prejuízo às demais propostas de regionalização em vigor, optou-se por nomear a área de investigação de Região Litorânea Central do Estado de Santa Catarina (figura 1): 


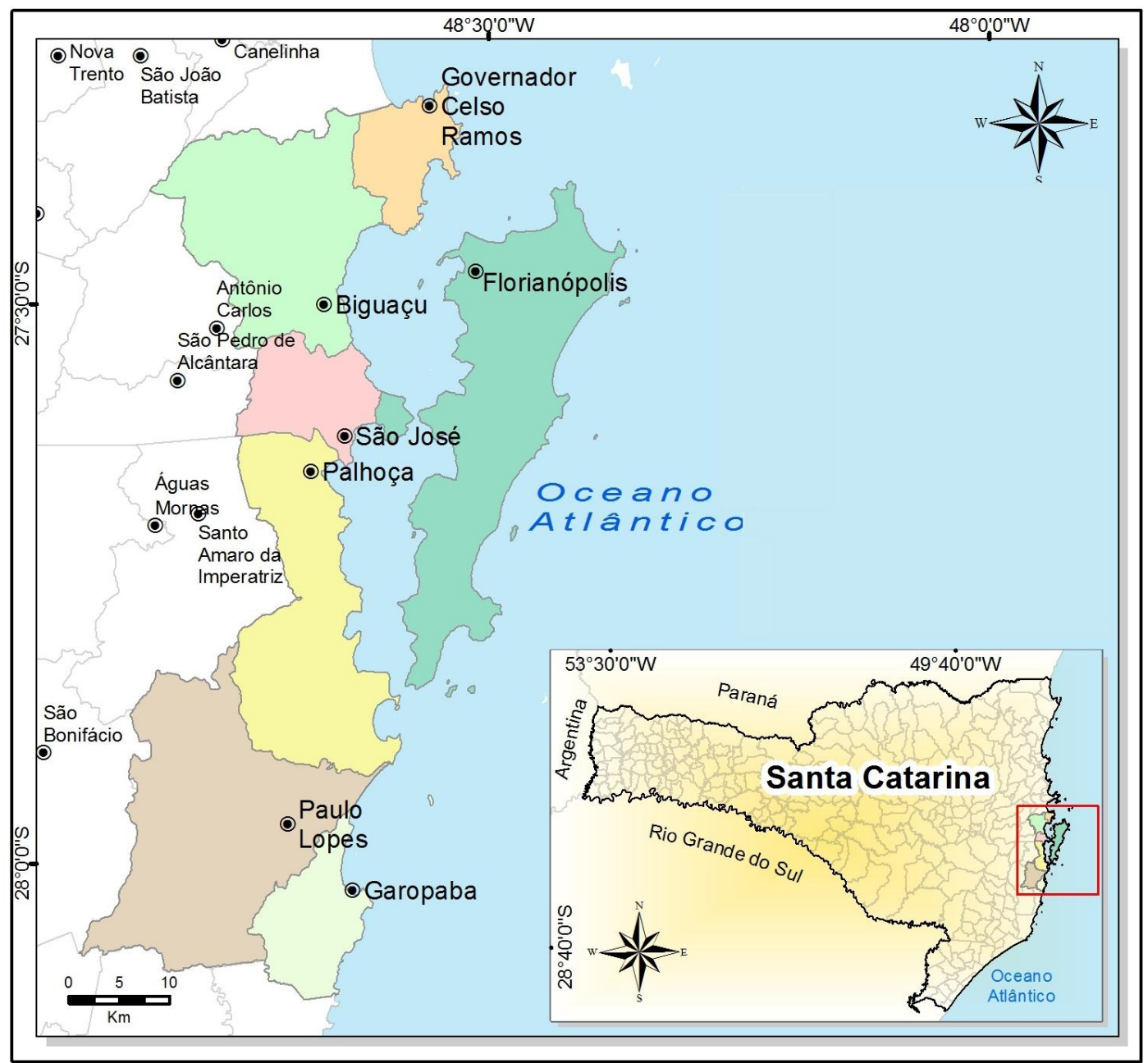

FIGURA 1 - REGIÃO LITORÂNEA CENTRAL DE SANTA CATARINA FONTE: ELABORADA PELOS AUTORES

Os municípios da referida região estabeleceram-se a partir da década de 1980 como importantes destinos turísticos do Estado. Nesses municípios, destaca-se ainda o turismo de temporada, sendo que durante a estação de verão amplia-se o número de estabelecimentos de serviços de alimentação para atendimento a turistas. Tais estabelecimentos se somam aos demais em atividade, de funcionamento permanente.

O turismo de temporada é responsável pela expansão dos postos de emprego nas atividades do turismo, ainda que temporários, além de contribuir para o crescimento da arrecadação fiscal dos municípios. De outra maneira, esse tipo de turismo garante uma segunda renda à parte da população residente que sobrevive da especulação imobiliária e dos trabalhos extras durante os meses de dezembro a março. Pela importância dessa fonte de rendimentos para a população em geral e para as cidades tocadas, o turismo no litoral central do Estado tem se apresentado como estratégia político-econômica com 
vistas ao desenvolvimento territorial local e regional. Vale acrescentar que os gastos dos turistas, conforme esclarece Sancho (2001), não se restringem às despesas com hospedagem, mas a uma variedade de serviços e bens de consumo: alimentos, transportes, entretenimentos, entre outros.

Todavia, apesar da importância da economia de serviços para os municípios, dados sobre as características e demandas dos diferentes segmentos desse mercado de trabalho em âmbito regional são escassos. Mesmo os planos governamentais para desenvolvimento da atividade turística não apresentam um panorama sobre a dimensão econômica das atividades relacionadas ao turismo nos municípios. Nesse contexto, não havia, até então, informações sobre o funcionamento do mercado de alimentação fora do lar nesse espaço. Tal situação justificou o esforço em um levantamento de dados de campo sobre esse mercado estruturado na caracterização do perfil profissional de trabalhadores, gestores e proprietários das empresas do referido ramo de atividades. A caracterização desses perfis é relevante tanto no sentido de se conhecer o grau de profissionalização do setor, quanto para avaliar suas exigências a fim de qualificar a atividade turística em escala local.

Em 2005, dados do levantamento realizado pelo IBGE (2008), mostraram que os serviços de alimentação representavam cerca de 19,5\% do valor acumulado pelas atividades do turismo no Brasil. Dentre às Atividades Características do Turismo (ACT), o segmento foi superado apenas pelos serviços de transporte rodoviário, que representavam aproximadamente $41,8 \%$ do valor acumulado. Em termos de referência, os serviços de alimentação adicionaram em torno de R\$ 25729 milhões ao valor acumulado pelas ACT, superando segmentos como os de serviços de transporte aéreo, ferroviário e metroviário, serviços de alojamento e as atividades de agências organizadoras de viagens.

Além disso, de acordo com levantamento (IBGE, 2008), os serviços de alimentação fora do lar foram os que mais se destacaram em número de postos de trabalhos entre as ACT, sendo que em 2005 respondiam por 37,79\% dos empregos, com 3066084 pessoas ocupadas. Por conseguinte, o segmento ocupava a segunda posição na participação dos rendimentos pagos: 17,7\% entre as ACT, ou seja, um montante de R\$ 9367 milhões, com 31,27\% dos trabalhadores com vínculo formal de emprego, o que demonstra a relevância do setor na geração de empregos no país. 
A importância econômica dos negócios de serviços de alimentação, contudo, não é condizente do ponto de vista da qualificação profissional com o perfil dos trabalhadores e empresários envolvidos com tal atividade. Segundo dados da Pesquisa Nacional por Amostra de Domicílios (IBGE, 1999), o setor é significativamente carente de pessoas qualificadas, tanto no âmbito da gestão quanto dos demais funcionários dos empreendimentos de Alimentos e Bebidas.

Em relação aos trabalhadores brasileiros, a PNAD (IBGE, 1999) revelou ainda que aqueles que atuavam em bares e restaurantes, por exemplo, tinham média de idade de 35 anos; menos de sete anos de estudo; cumpriam jornadas de trabalho de 48 semanais e recebiam até 2,5 salários mínimos. Tratava-se, portanto, de trabalhadores adultos, com experiência no mercado de trabalho, mas pouco escolarizados. Em decorrência disso, infere-se que a baixa escolaridade repercute em um mercado de mão de obra em serviços de alimentação pouco especializada, composta por trabalhadores que se sujeitavam a trabalhar por salários modestos e a cumprir jornadas além da regulamentada, de 44 horas semanais ou mais.

Quanto ao perfil dos gerentes e empresários, a pesquisa mostrou que a estrutura simples dos estabelecimentos no mercado brasileiro de bares e restaurantes repercutem em mais de $40 \%$ deles a concomitância de proprietários como funcionários nos negócios em que administram. Nesse sentido, donos e gestores desses estabelecimentos devem ser considerados como potencial demanda para capacitação, não devendo às ações se restringirem aos empregados. Por outro lado, não se descarta que mesmo em se tratando de empresários ou gestores que não executam atividades operacionais, a formação para a administração do negócio por meio de conhecimento sobre o mercado na área de alimentação é desejável.

Considerando o mencionado contexto, a fim de levantar dados sobre o mercado de alimentação fora do lar na Região Litorânea Central de Santa Catarina, a pesquisa aqui apresentada, concebida no ano de 2007 e executada entre outubro de 2008 e março de 2009, procurou avaliar a qualificação dos profissionais do setor. Esses dados, até então organizados em um relatório de planilhas eletrônicas e tabulação gráfica, não haviam, entretanto, recebido uma análise de indicadores mais apurada. Ao mesmo tempo, considerando a circulação do material exclusivamente entre os pesquisadores, $\mathrm{o}$ acesso aos resultados do levantamento foi por cerca de dois anos ocasional e restrita. 
Vale salientar que a pesquisa foi encaminhada pelo Instituto Federal de Santa Catarina (IFSC), com o propósito de planejar e balizar a oferta de cursos profissionalizantes para as atividades do turismo, especialmente para o setor de alimentação fora do lar no município de Florianópolis e região do entorno costeiro. Tais objetivos fizeram do material importante instrumento de gestão acadêmica. Contudo, a dificuldade em buscar informações complementares e dados primários de apoio contribuiu para uma análise do material coletado e, principalmente, o esforço em divulgá-lo para a comunidade científica interessada pelo tema.

Os resultados da pesquisa, os quais desencadearam outros estudos a partir deles (ROCHA et al., 2010; ROCHA e JACQUES, 2011), estão fundamentados em dados coletados em campo e da avaliação inédita do quadro de qualificação profissional na Região Litorânea Central de Santa Catarina. Localmente, espera-se que seu conteúdo possa contribuir para a expansão e qualificação das políticas de turismo nos municípios. Em sentido mais amplo, almeja que possam contribuir para a análise sobre o setor de alimentação fora do lar no Brasil junto aos demais estudos regionais e locais relacionados o tema.

\section{MÉTODO}

A pesquisa foi realizada em sete municípios da região litorânea de Santa Catarina. Participaram da pesquisa funcionários, gestores e proprietários de estabelecimentos de alimentação fora do lar. Considerou-se como setor de alimentação fora do lar aquele relacionado aos serviços de alimentação em estabelecimentos comerciais que atuam no varejo. Por sua vez, consideraram-se trabalhadores do setor de serviços de alimentação aqueles que estão empregados nas diferentes áreas da alimentação fora do lar, dentre eles cozinheiros, auxiliares de cozinha, maîtres, garçons, barmen, padeiros e confeiteiros. Para a caracterização das empresas, consultaram-se os proprietários e os gerentes dos estabelecimentos, nas situações em que a administração estava sob responsabilidade de um terceiro.

Os dados foram coletados por meio de dois instrumentos de pesquisa com questões fechadas. No total foram respondidos 1.516 questionários, dos quais 1.110 
$(73,22 \%)$ por funcionários e $406(26,78 \%)$ por gestores ou proprietários, entre novembro de 2008 e março de 2009. O método de amostragem utilizado foi o da estratificação proporcional por tipologia de estabelecimento. Dessa maneira, a amostra envolveu 406 empresas agrupadas nas seguintes categorias: a) restaurantes; b) bares, lanchonetes, drives e casas noturnas; c) panificadoras e confeitarias:

\begin{tabular}{|c|c|c|}
\hline \multicolumn{1}{|c|}{ Tipologia do estabelecimento } & "n” & $\%$ \\
\hline Restaurantes & 146 & 35,96 \\
\hline Restaurante internacional & 18 & 4,43 \\
\hline Restaurante típico & 58 & 14,29 \\
\hline Restaurante self service & 73 & 17,98 \\
\hline Bares, Lanchonetes, Drives e Casas Noturnas & 201 & 49,51 \\
\hline Lanchonete & 104 & 25,62 \\
\hline Bar e casa noturna & 97 & 23,89 \\
\hline Panificadoras e Confeitarias & 59 & 14,53 \\
\hline T O T A L & 406 & 100,00 \\
\hline
\end{tabular}

FIGURA 2 - NÚMERO DE ESTABELECIMENTOS PESQUISADOS

FONTE: PESQUISA DE CAMPO 2008-2009

\section{RESULTADOS}

A profissionalização dos trabalhadores e gestores nas atividades do turismo é apontada como condição fundamental para o desenvolvimento setor. Disso resulta a importância dos programas de educação que visem à qualificação do corpo técnico nele empregado. Nesse contexto, a qualificação técnica dos trabalhadores e gestores nas atividades do turismo está diretamente vinculada à melhoria do sistema de prestação de serviços e, por conseguinte, à satisfação dos clientes nos destinos. (SANCHO, 2001).

Entretanto, o mercado de trabalho de alimentação fora do lar, um dos principais segmentos do turismo, permanece sendo caracterizado pela escassa qualificação associada a contratos e condições de emprego pouco atraentes para os profissionais que atuam na área. O referido quadro de desvalorização profissional não é uma realidade apenas brasileira, mas observada também em demais países, entre os quais europeus. Segundo Sancho (2001), as condições desfavoráveis de emprego nos setores de hotelaria, alimentação, e do turismo em geral repercutem negativamente no setor, pois são responsáveis por produzir uma elevada taxa de abandono na mão de obra ocupada. Assim, "na Inglaterra calcula-se que aproximadamente $40 \%$ do pessoal abandona o 
emprego depois de um ano, enquanto na França, se constata que continua sendo um setor de passagem ou primeiro acesso para os jovens". (SANCHO, 2001, p. 353).

A fim de contribuir para a reversão desse cenário, particularmente no Litoral Central Catarinense, os resultados, apresentados e discutidos a seguir, procuram contribuir para a reflexão sobre o quadro geral da atividade. A análise dos dados oferece uma leitura conjuntural do mencionado mercado e, espera-se, poderão subsidiar políticas de intervenção, pesquisas de aprofundamento ou estudos comparativos do levantado com a realidade diagnosticada em demais áreas por pesquisadores interessados no tema.

\subsection{PERFIL PROFISSIONAL DOS TRABALHADORES DO SETOR DE} ALIMENTAÇÃO FORA DO LAR NA REGIÃO LITORÂNEA CENTRAL DE SANTA CATARINA

Os trabalhadores do setor de alimentação fora do lar na região estudada possuíam, em geral, pouca escolaridade: $63 \%$ deles não haviam concluído o ensino médio e apenas 3\% tiveram alguma formação de nível superior (figura 3):

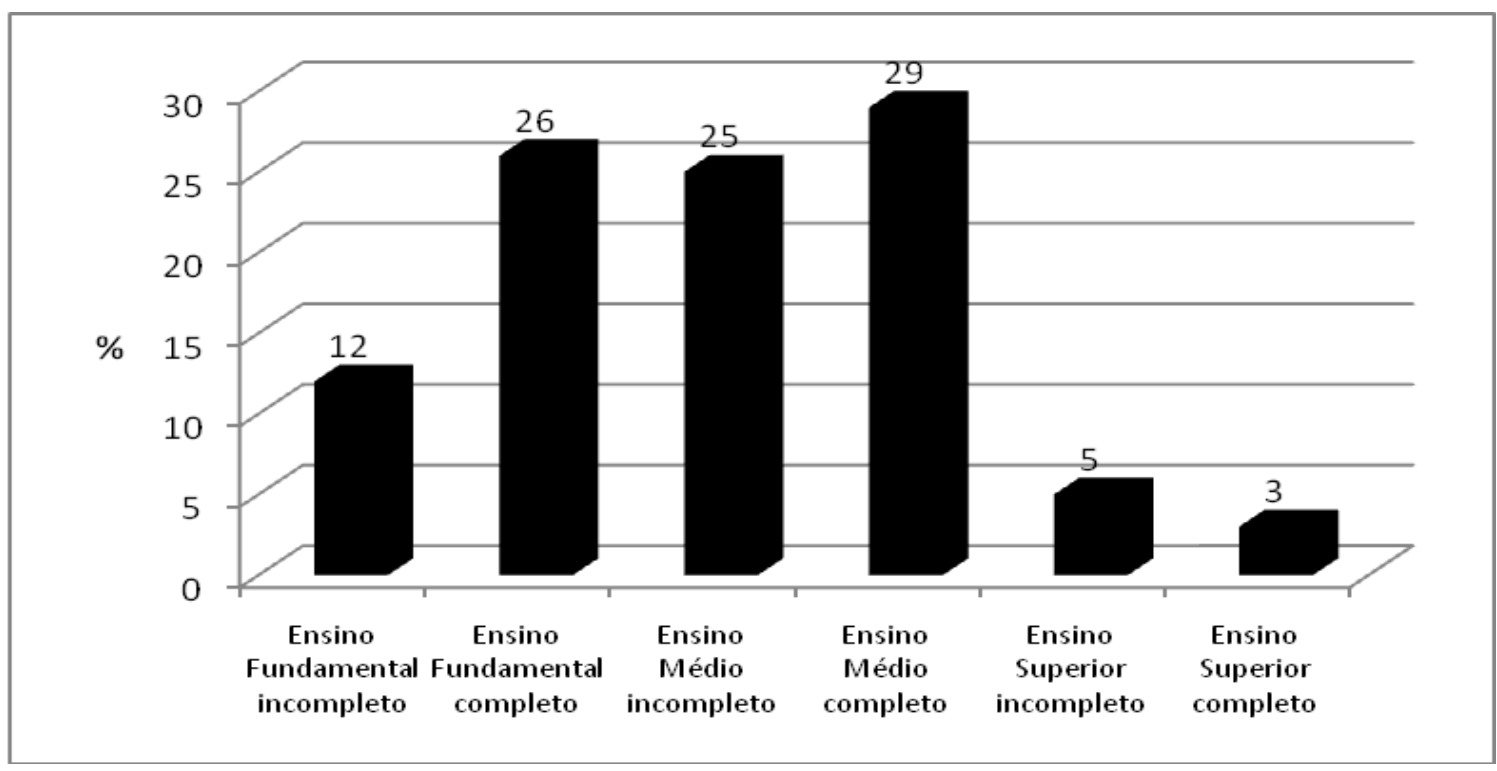

FIGURA 3 - ESCOLARIDADE DOS TRABALHADORES

FONTE: PESQUISA DE CAMPO 2008-2009

Alinhados às conclusões de Teles e Arbache (2004), os dados expõem uma característica do setor: a inserção de trabalhadores em condição de vulnerabilidade 
social que, em função disso, submetem-se às mais precárias condições de emprego e renda. De maneira geral, tratava-se de trabalhadores com possibilidades de escolhas profissionais reduzidas e que em função disso vendiam sua força de trabalho a qualquer preço. Assim, constatou-se que o mercado de trabalho de alimentação fora do lar na região em destaque remunerava mal a mão de obra empregada, ao passo que os trabalhadores da área, camuflados no discurso do "dom" para cozinhar e servir, pouco reivindicavam a valorização pelo ofício que realizavam. Por outro lado, a escolaridade insuficiente desses trabalhadores, aliada a não qualificação para as atividades profissionais que desempenhavam, resultava em uma frágil representação classista da categoria. (ROCHA et al., 2010).

Entre os trabalhadores que atuavam no setor, $76 \%$ deles estavam empregados há menos de três anos, sendo que desses, $45 \%$ estavam contratados há menos de doze meses. Aplicada a variável tempo para intervalos superiores, percebeu-se como exceção a continuidade dos trabalhadores nos estabelecimentos: somente $10 \%$ afirmaram permanecer ocupados no setor além de nove anos (figura 4):

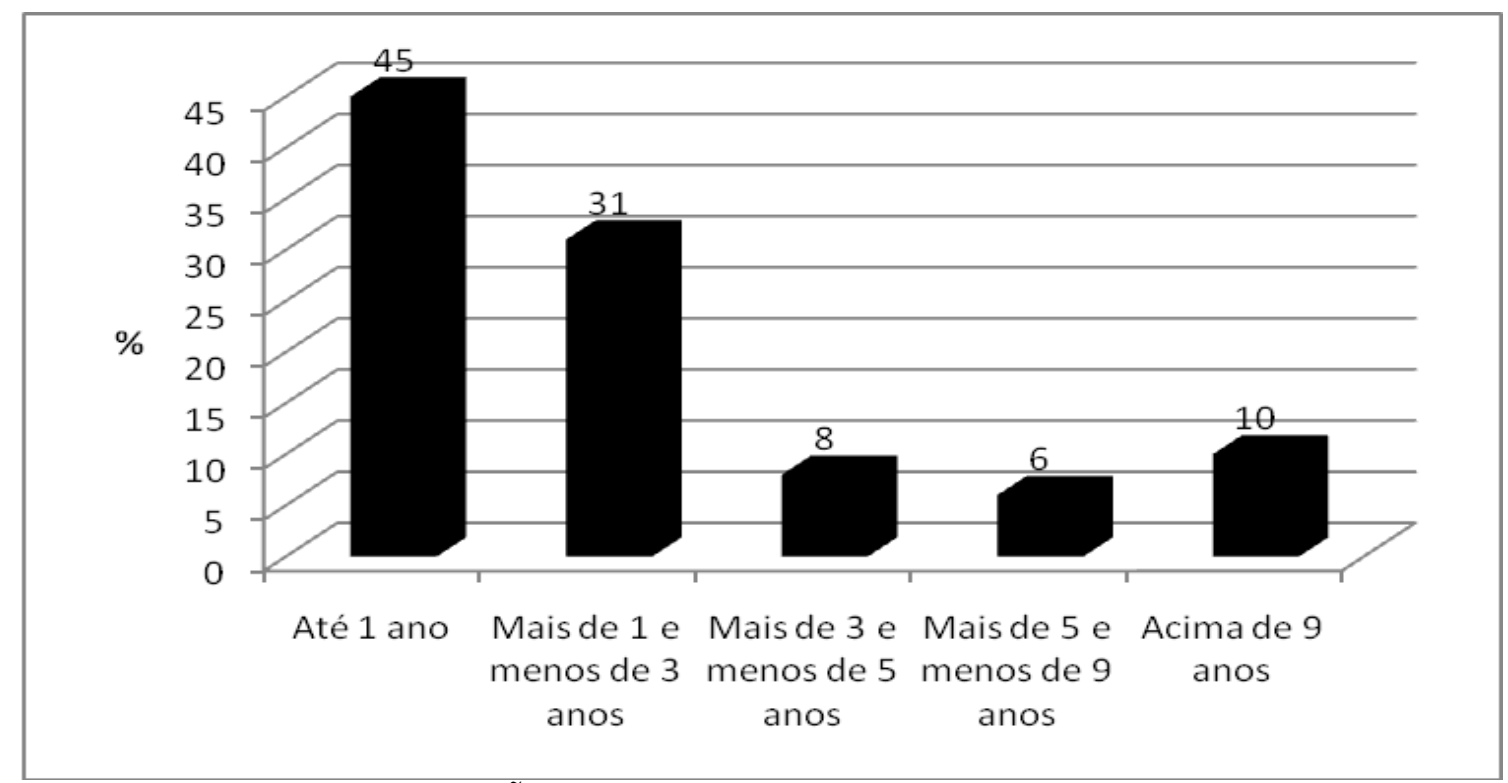

FIGURA 4 - TEMPO DE ATUAÇÃO NO SETOR

FONTE: PESQUISA DE CAMPO 2008-2009

Conforme Rocha e Jaques (2011), a desvalorização salarial da mão de obra especializada pelo empresariado, os baixos salários pagos e a ausência de perspectiva de ascensão na carreira, são fatores influentes na opção dos trabalhadores desse mercado em não investir na verticalização da formação profissional. Nessa direção, pesquisa com 
os egressos de cursos técnicos constatou que entre aqueles que se empregaram depois de formados, $79 \%$ deles ficaram menos de um ano nos estabelecimentos em que foram contratados. (ROCHA e JAQUES, 2011).

A constatação da pequena permanência dos profissionais qualificados no setor repercute em um mercado formado por trabalhadores desqualificados. Nesse sentido, os dados levantados na pesquisa de mercado realizados entre 2008 e 2009 revelaram que da força de trabalho ocupada, apenas $27 \%$ realizou algum tipo de formação para as atividades que desempenhava. Nessa proporção estão incluídos cursos com quaisquer cargas-horárias, entre os quais de higiene e manipulação de alimentos ou treinamentos concedidos por empresas fornecedoras de insumos e assessorias contratadas pelos empregadores. Ainda assim, 73\% dos entrevistados afirmaram não possuir qualquer qualificação para a função ocupada no estabelecimento (figura 5):

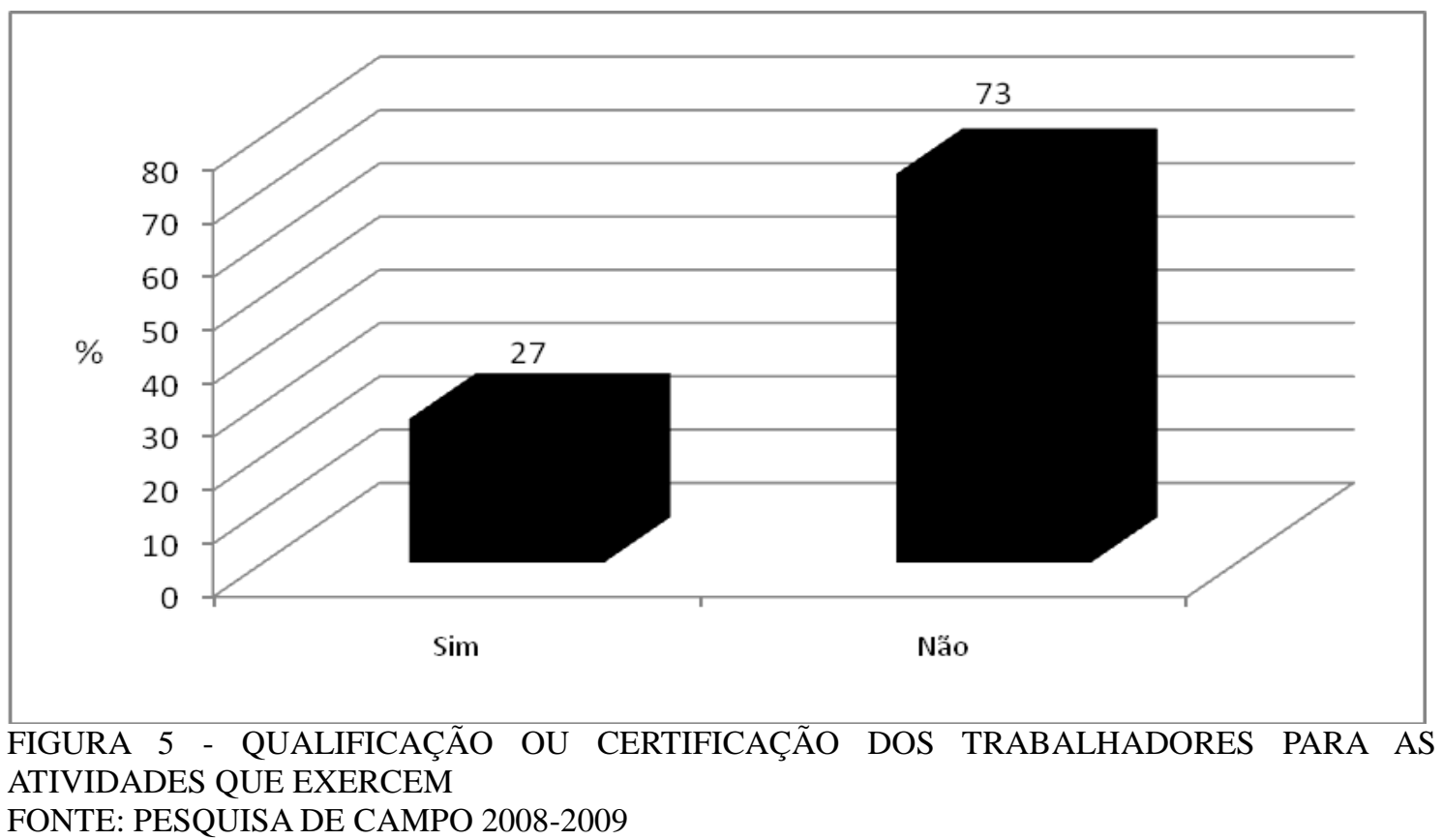

Diante disso, inferiu-se que a qualificação técnico-profissional dos trabalhadores era escassa, sendo que a qualificação insuficiente, por sua vez, repercutia no rebaixamento geral dos salários pagos. Nessa direção, vale destacar que $83 \%$ dos entrevistados afirmaram receber até 3 salários mínimos mensais, sendo que 59\% deles recebiam até 1,5 salário mínimo: 


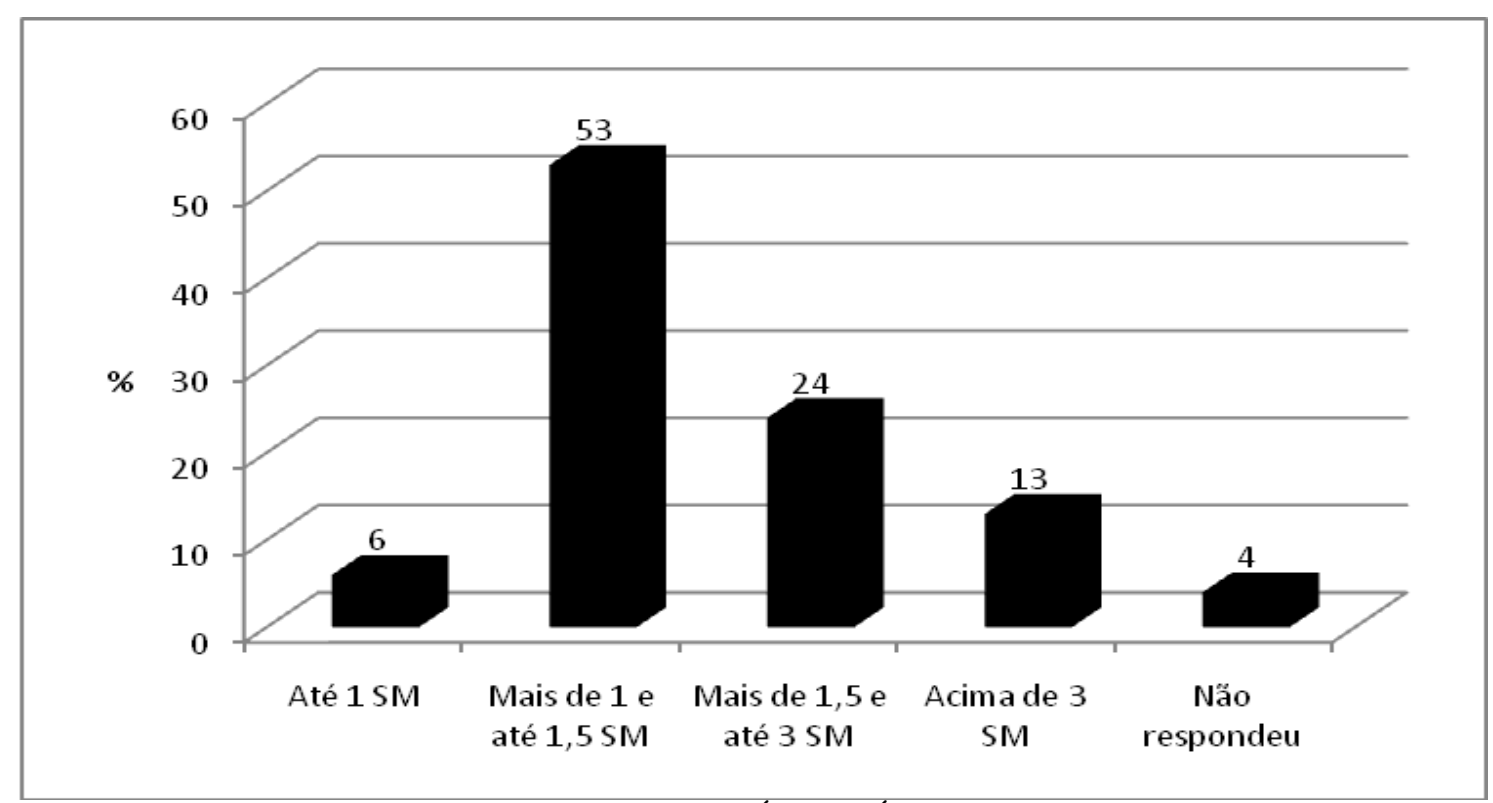

FIGURA 6 - FAIXAS DE VENCIMENTO EM SALÁRIO MÍNIMO [SM]

FONTE: PESQUISA DE CAMPO 2008-2009

Em estudo realizado pelo Ministério da Educação no ano de 2008 com egressos de cursos técnicos em indistintas áreas de atuação (BRASIL, 2008), constatou-se que $57 \%$ deles recebiam mensalmente até três salários mínimos e $39 \%$ até dois salários mínimos ou menos. Dessa maneira, pode-se avaliar que os trabalhadores do setor de alimentação fora do lar na Região Litorânea Central de Santa Catarina estavam posicionados na faixa de vencimento-padrão paga a funcionários de nível operacional. Contudo, se os salários iniciais para trabalhadores de nível técnico no setor de turismo são equivalentes à remuneração de trabalhadores de nível técnico dos demais setores, o mesmo não ocorre em cargos de nível superior. Nesse sentido, diferente do que acontece nas demais áreas, em que a graduação universitária estabelece um patamar mais elevado de cargos e salários, nos postos de emprego no turismo o padrão de vencimentos entre técnicos e graduados não se altera.

Convém registrar, sobre os dados apresentados pela pesquisa que, como de praxe, é provável que parte desses trabalhadores tenha vencimentos acima do legalmente registrado em razão das gratificações e gorjetas recebidas. Para efeito desse estudo, tais valores não foram, porém, mensurados ou considerados.

Por outro lado, muitas vezes as funções desempenhadas pelos trabalhadores extrapolam os cargos para os quais foram contratados. Nesse estudo levantou-se que a compatibilidade função/cargo situou-se em $71 \%$ dos casos, ou seja, para um grupo de 
100 trabalhadores que desempenhavam a função de auxiliar de cozinha, por exemplo, apenas 71 eram contratados para esse cargo, sendo que os demais 29 não desempenhavam a função ou a desempenhavam concomitantemente a outra função. Esse dado reforça a característica familiar dos negócios no setor de alimentação fora do lar na área de estudo em que, em geral, a mão de obra empregada exerce no estabelecimento tarefas além daquelas para as quais foram contratadas.

Nessa direção, de acordo com os resultados da pesquisa, apenas cinco entrevistados afirmaram terem sido contratados para a função de auxiliar de limpeza. Apesar disso, 222 atuavam como tal. Tendo em vista relatos de profissionais da área, cogita-se que parte desses trabalhadores era também responsável pela limpeza dos estabelecimentos em que trabalhavam. Segundo Aquino (2009), a polivalência é uma das marcas da mão de obra operacional empregada nas atividades do turismo. Assim, esses trabalhadores são contratados para executar os mais diferentes tipos de serviço e ocupar as mais diversas funções nas empresas. A baixa especialização é fator decisivo para a desvalorização profissional dos trabalhadores do turismo à medida que essa concepção remete à ideia de que as funções por eles exercidas podem ser realizadas por qualquer um, com ou sem qualificação, a qualquer tempo e a qualquer custo.

\subsection{PERFIL DOS GESTORES E PROPRIETÁRIOS DE EMPRESAS DE} ALIMENTAÇÃO FORA DO LAR NA REGIÃO LITORÂNEA CENTRAL DE SANTA CATARINA

Entre os diferentes segmentos de mercado no setor de alimentação fora do lar no na Região Litorânea Central de Santa Catarina, sobressaem restaurantes, lanchonetes, bares e casas noturnas, panificadoras e confeitarias: 


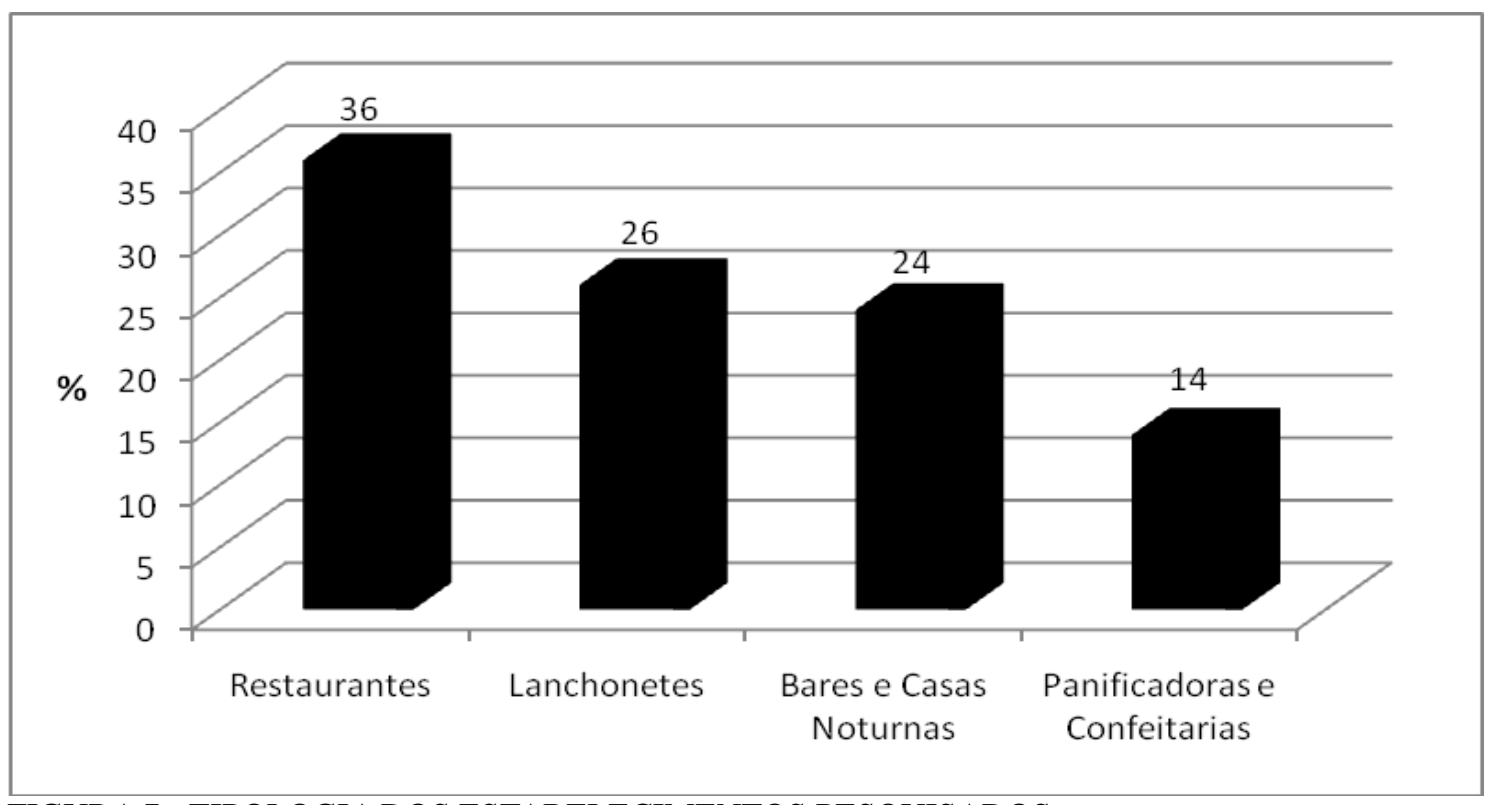

FIGURA 7 - TIPOLOGIA DOS ESTABELECIMENTOS PESQUISADOS

FONTE: PESQUISA DE CAMPO 2008-2009

Sobre a natureza desses estabelecimentos, constatou-se que parte deles atuava no mercado simultaneamente como restaurante e bar, bar e casa noturna, lanchonete e bar ou como panificadora e confeitaria. Se por um lado essa característica pode sinalizar falta de segmentação, por outro, procura corresponder às expectativas dos consumidores que podem encontrar em um mesmo lugar opções de café da manhã, lanche, refeição completa e bebidas.

Além disso, os estabelecimentos estavam marcados pelo intensivo uso de mão de obra. Cada empresa, individualmente, empregava um pequeno número de pessoas: $66 \%$ dos estabelecimentos pesquisados contavam com até 10 funcionários, 33\% operavam com 11 a 40 funcionários e apenas 1\% empregava mais de 40 trabalhadores. Tratava-se, portanto, de pequenas empresas ${ }^{1}$, predominantemente familiares.

A respeito da longevidade dos estabelecimentos, verificou-se que cerca de $12 \%$ deles iniciaram as atividades antes da década de 1990, e 20\% entre 1991 e 2000. Contudo, foi na última década que se presenciou expansão significativa no número de empresas, haja vista que $68 \%$ das pesquisadas ingressaram no mercado entre 2000 e 2009.

\footnotetext{
${ }^{1}$ Nas atividades de comércio e serviços são classificadas como pequenas empresas aquelas que possuem entre 10 e 49 funcionários. SEBRAE (2011).
} 


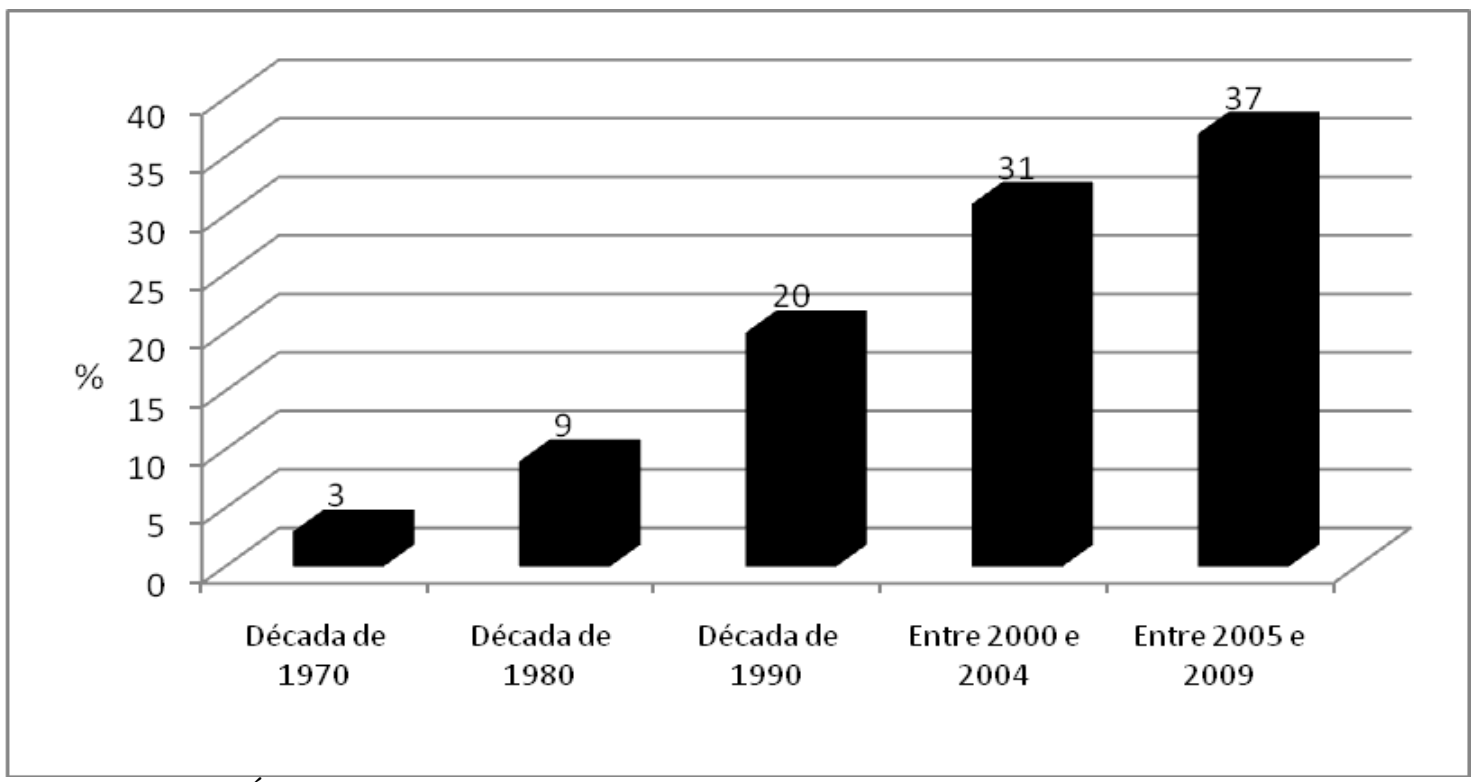

FIGURA 8 - PERÍODO DE ABERTURA DAS EMPRESAS

FONTE: PESQUISA DE CAMPO 2008-2009

É preciso considerar, entretanto, que os dados expostos não permitiram avaliar a dinâmica de abertura e fechamento dos negócios. Dessa maneira, embora se reconheça a possibilidade de as últimas décadas terem de fato propiciado as condições para expansão de empresas de alimentação fora do lar, tendo em vista o crescimento da economia ligada ao turismo e a nova rotina das famílias que optam por fazer parte de suas refeições diárias no próprio ambiente de trabalho ou próximo a ele, os negócios na área têm apresentado, em geral, dificuldades em se manter no mercado. Tais dificuldades estão relacionadas, entre outros aspectos, à falta de experiência do empresariado na gestão de negócios de alimentação, à sazonalidade de clientela e a má gerência de recursos financeiros e humanos. Convém observar, nesse sentido, que 55\% dos gestores e proprietários dos estabelecimentos consultados não tinham qualquer experiência de trabalho ou investimento no setor anterior ao empreendimento atualmente administrado. Diante disso, as maiores dificuldades que mencionaram na gestão dos estabelecimentos estavam relacionadas ao controle da produção, das contas a pagar e a receber, ao recrutamento e seleção de funcionários, ao planejamento e controle dos estoques e à determinação de preço de custo e venda das mercadorias.

Quanto à capacitação dos recursos humanos, apenas 35\% das empresas consultadas proporcionavam algum tipo de treinamento aos funcionários. Entre os treinamentos oferecidos, cerca de $63 \%$ do total eram cursos de higiene e manipulação de alimentos. Destacavam-se ainda os treinamentos oferecidos por fornecedores de 
insumos (28\%). Por sua vez, 55\% dos treinamentos aconteceram no início da contratação, caracterizando o chamado "passar o serviço", momento em que o funcionário tomava ciência das rotinas de trabalho na empresa. Em relação à periodicidade da formação, $15 \%$ das empresas ofereciam treinamento uma vez a cada dois meses, $19 \%$ a cada semestre e $4 \%$ anualmente:

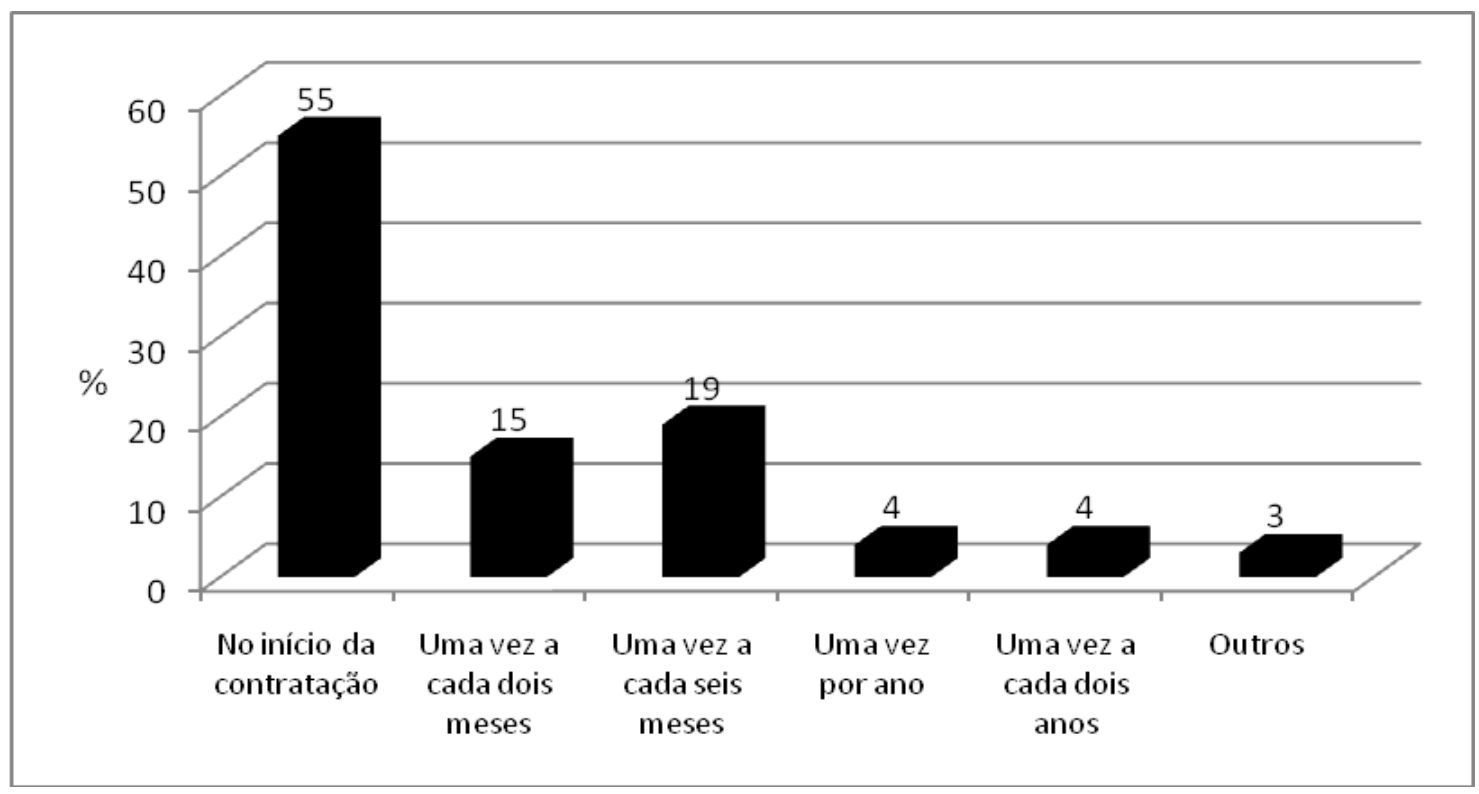

FIGURA 9 - PERIODICIDADE DE TREINAMENTO

FONTE: PESQUISA DE CAMPO 2008-2009

Vale destacar que entre os segmentos de mercado de alimentação fora do lar, o de confeitaria é aquele que responde pelos maiores investimentos em qualificação para os trabalhadores da área. Uma interpretação para esse dado pode estar relacionada às exigências de domínio técnico, à sofisticação e a necessidade de ampliação dos repertórios de criação e inovação de produtos na área. Em contrapartida, a panificação é o segmento em que menos se observa empenho dos empresários em qualificar a mão de obra empregada.

Para o recrutamento e seleção de funcionários, os requisitos para a contratação apontados pelos proprietários e gestores do setor, em ordem de relevância, foram: a qualificação profissional, seguida da experiência, da proximidade de moradia e das referências apresentadas pelos candidatos: 


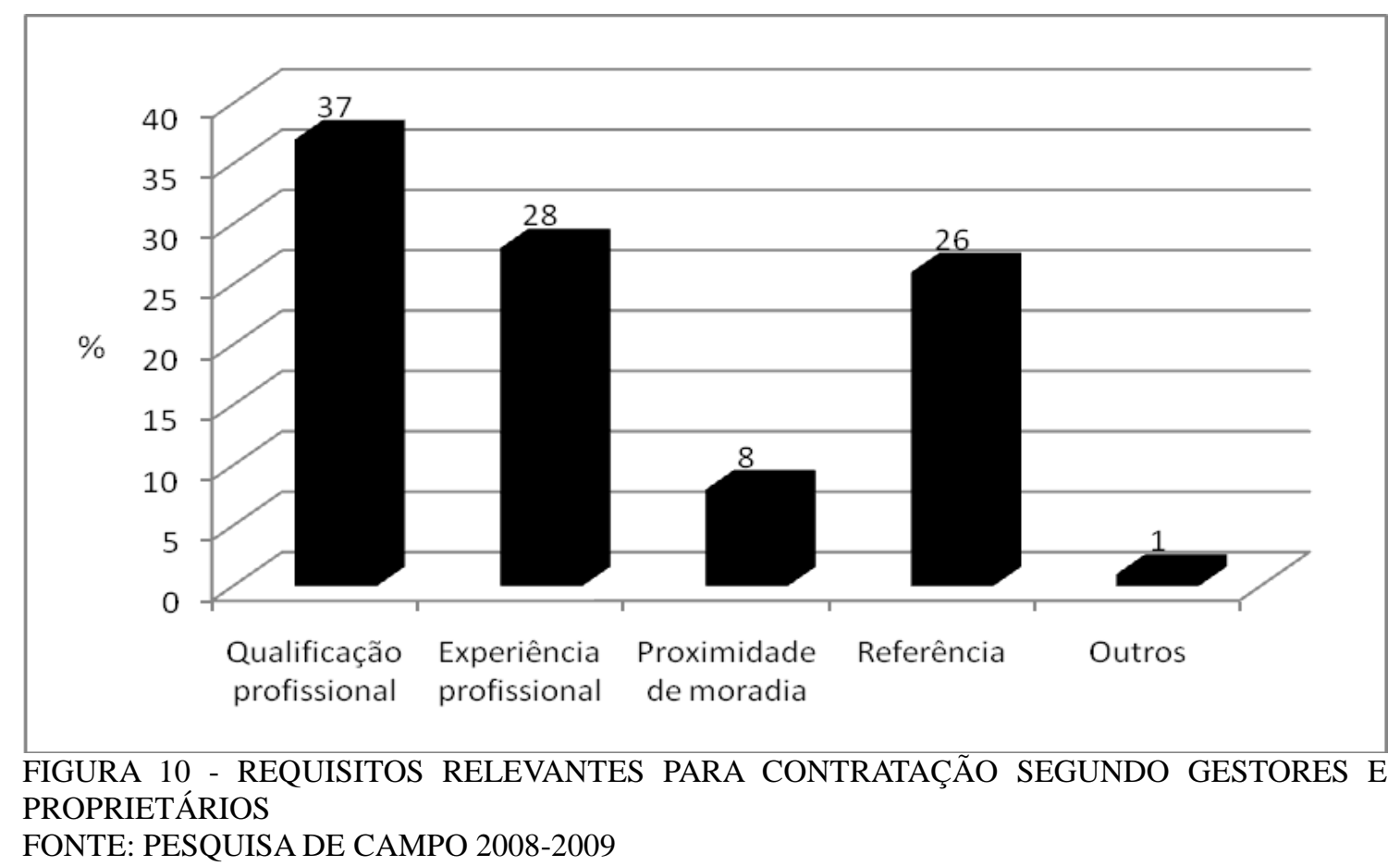

Apesar de a qualificação profissional constituir-se pré-requisito principal para a contratação, não é incomum que devido à escassez de mão de obra especializada disponível aconteça a substituição desse critério por outro, em particular pelo tempo de experiência de trabalho na área. A fim de confirmar esse dado, ressalta-se que pesquisa realizada com 74 egressos de cursos técnicos da área de alimentação fora do lar mostrou que apenas 17 ingressaram no mercado de trabalho depois de formados. (ROCHA e JAQUES, 2011). Tal dado evidencia a modesta a inserção dos profissionais qualificados no mercado de trabalho em questão.

A referência apresentada pelo trabalhador (indicação ou recomendação pelo contratante anterior) era, por sua vez, cogitada como requisito principal para contratação principalmente nas pequenas empresas familiares. Em outra direção, a proximidade de moradia era requisito decisivo nos locais mais afastados, onde a disponibilidade de transporte público era limitada ou houvesse horário incerto de encerramento do expediente de trabalho, como acontece em bares, pizzarias, restaurantes e drives que funcionam durante o período noturno.

Positivamente, verificou-se que a mão de obra especializada em serviços de alimentação não encontrava dificuldades em se inserir no mercado. Ao contrário, a baixa especialização da área aliada à expansão dos postos de emprego, eram fatores favoráveis à empregabilidade. Entrevistas com o empresariado local mostraram que a 
qualificação profissional repercutia na garantia de emprego do trabalhador, especialmente considerando as dificuldades atuais de atração pelo mercado da força de trabalho tecnicamente capacitada. Todavia, frente à expectativa de profissionalização do setor, verificou-se ser necessário o esforço do empresariado em proporcionar incentivos para a formação dos trabalhadores, bem como maior valorização da mão de obra ocupada.

\section{CONSIDERAÇÕES FINAIS}

A respeito do perfil profissional e socioeconômico dos trabalhadores do setor de alimentação fora do lar nos municípios de estudo, a pesquisa constatou o seguinte: a) serem pertinentes investimentos em formação escolar e qualificação profissional dos trabalhadores, haja vista que $63 \%$ deles não haviam concluído o ensino médio e $73 \%$ deles não possuíam formação específica para as atividades que desempenhavam; b) considerando que 59\% dos trabalhadores entrevistados recebiam até 1,5 salário mínimo mensal, planos de cargos e salários mais atrativos por parte do empresariado se mostraram fundamentais a fim de viabilizar a formação técnica e contribuir para a profissionalização do setor; c) a desvalorização por parte do empresariado dos trabalhadores tecnicamente formados repercutiu no desinteresse dessa população pela qualificação profissional. Além disso, os resultados revelaram que decorridos o período de nove anos, apenas um, entre dez ingressantes no mercado de trabalho permanecia atuando no setor.

Em relação ao perfil das empresas, a pesquisa constatou que os restaurantes representaram a maior parcela do mercado de alimentação fora do lar na região investigada, acompanhados de lanchonetes, bares, casas noturnas e panificadoras e confeitarias. De maneira geral, tais empresas haviam tido inserção recente no mercado, sendo $68 \%$ delas inauguradas a partir do ano 2000. Nesse mercado, o levantamento do perfil dos proprietários e gestores mostrou que: a) predominou o perfil de administradores de empresas classificadas como de pequeno porte: $66 \%$ das empresas mantinham até 10 funcionários e $99 \%$ até 40 contratados; b) apenas $35 \%$ dos gestores e proprietários afirmaram proporcionar algum tipo de treinamento aos funcionários; c) a 
qualificação, citada por $37 \%$ dos entrevistados, seguida pela experiência (28\%) e a referência profissional $(26 \%)$, foram os critérios prioritários apontados pelos gestores e proprietários para recrutamento de funcionários nos estabelecimentos.

Atualmente, o perfil de qualificação profissional no setor de alimentação fora do lar na região pesquisada não tem mostrado indicadores satisfatórios de mudança. Em estudo realizado por Rocha et al. (2010), sobre o perfil de trabalhadores de cozinha da Via Gastronômica de Coqueiros, no município de Florianópolis, atestou-se a necessidade de elevação da escolaridade desses trabalhadores, considerando que 54\% não possuíam o ensino fundamental e $75 \%$ não haviam completado o ensino médio. Além disso, 79\% dos entrevistados recebiam até dois salários mínimos e meio mensais enquanto cerca de um terço deles não possuíam nenhum tipo de formação para as atividades que exerciam. Entre os que mencionaram possuir algum curso de qualificação profissional, $51 \%$ deles eram cursos de higiene e manipulação de alimentos de até 50 horas.

Por sua vez, pesquisa realizada por Rocha e Jacques (2011), com egressos de cursos técnicos de cozinha, serviços de bar e restaurante, panificação e confeitaria do IFSC, Campus Florianópolis - Continente, constatou que a formação técnica não tem sido capaz de contribuir para a mudança no perfil de contratação e valorização profissional desse tipo de trabalhador pelo empresariado local. Nessa direção, as más condições de emprego, aliadas aos baixos salários e à valorização profissional têm contribuído para que a maioria dos trabalhadores qualificados abandone a área de atuação até um ano depois da primeira experiência de emprego. Essa situação repercute na ocupação dos postos de trabalho do setor de alimentação fora do lar pela mão de obra desqualificada que, justamente por tal condição, se sujeita aos mais precários contratos de trabalho. Ainda sobre a qualificação profissional dos trabalhadores, Silva (2012), levantou em investigação realizada com cozinheiros e auxiliares de cozinha de 153 restaurantes do litoral de Santa Catarina, que apenas 35 deles $( \pm 11,5 \%$ da população pesquisada), possuíam qualificação profissional na área de gastronomia.

A fim de reverter o referido quadro, torna-se essencial a qualificação também dos gestores e proprietários dos negócios. Entre os proprietários, principalmente, alguns investem na área por terem capital, mas são inexperientes ou desconhecedores desse mercado; outros são levados pelo "canto da sereia", ou seja, porque são apreciadores da 
boa mesa, pensam que administrar negócios nessa área pode ser tão prazeroso quanto comer e beber em um restaurante como clientes. (ROCHA e JACQUES, 2010).

Nesse contexto, avalia-se como pertinente executar programas de capacitação profissional para trabalhadores, gestores e proprietários envolvidos com o setor de alimentação fora do lar na área de estudos. Por outro lado, é pertinente a concepção de indicadores que permitam obter dados relacionados à qualidade dos serviços oferecidos aos turistas e à população residente, bem como índices de análise da qualificação técnico-profissional da mão de obra empregada.

\section{REFERÊNCIAS:}

AQUINO, C. A. B. de. Reestruturação da temporalidade laboral a partir do discurso dos trabalhadores do turismo. Cadernos de Psicologia Social do Trabalho, São Paulo, v. 12, n. 2, p. 271-283, dez. 2009.

BRASIL. Pesquisa Nacional de Egressos dos Cursos Técnicos da Rede Federal de Educação Profissional e Tecnológica (2003-2007). FERES, C. N.; PATRÃO; M. M. (Orgs.). Ministério da Educação: Secretaria de Educação Profissional e Tecnológica. Brasília, DF, 2008. 57 p.

IBGE. INSTITUTO BRASILEIRO DE GEOGRAFIA E ESTATÍSTICA. Economia do Turismo: uma perspectiva macroeconômica 2000-2005. Rio de Janeiro, IBGE, 2008.

Pesquisa Nacional por Amostra de Domicílios (PNAD): síntese de indicadores sociais. Rio de Janeiro, IBGE, 1999.

Mapas Político-Administrativos Regionais: Região Sul. Disponível em: <http://www.ibge.gov.br/mapas_ibge/pol.php>. Acesso em: 20/03/2012.

PEREIRA, R. M. F. do A. Formação sócio-espacial do litoral de Santa Catarina (Brasil): gênese e transformações recentes. Geosul, Florianópolis, v. 18, n. 35, p. 99129, jan./jun.2003.

ROCHA, F. G.; RIBAS, L. C. C.; ROCHA, A. das C. Perfil dos trabalhadores de cozinha da via gastronômica de Coqueiros e notas sobre a qualificação profissional no setor de alimentos e bebidas no município de Florianópolis SC. Revista Brasileira de Pesquisa em Turismo, v. 4, n. 3, p. 24-40, dez., 2010.

ROCHA, F. G.; JAQUES, J. S. D. Qualificação e inserção profissional de egressos de cursos técnicos no mercado de trabalho de serviços de alimentação e hospedagem no município de Florianópolis, SC. In: SEMINÁRIO DA ASSOCIAÇÃO NACIONAL DE 
PESQUISA E PÓS-GRADUAÇÃO EM TURISMO, 8., 2011, Balneário Camboriú. Anais... Balneário Camboriú, UNIVALI, 2011. p. 1-12.

SANCHO, A. Introdução ao Turismo. ORGANIZAÇÃO MUNDIAL DO TURISMO (OMT). Traduzido por Dolores Martin Rodrigues Corner. São Paulo: Roca, 2001.

SANTUR. SANTA CATARINA TURISMO S/A. Destinos. Disponível em: <http://www.santur.sc.gov.br/>. Acesso em: 20/03/2012.

SILVA, M. K. da. Aproveitamento gastronômico de peixes oceânicos de ocorrência local no Litoral de Santa Catarina. 138 f. Dissertação (Mestrado em Turismo e Hotelaria). Programa de Pós-Graduação em Turismo e Hotelaria, Univali, Itajaí, 2012.

SEBRAE. SERVIÇO BRASILEIRO DE APOIO ÀS MICRO E PEQUENAS EMPRESAS. Classificação Empresarial. Disponível em: <www.sebrae.com.br/goias/classificação>. Acesso em: 08/09/2011.

TELES, V. K.; ARBACHE, J. S. A economia brasileira e a gastronomia. In: CONGRESSO BRASILEIRO DE GASTRONOMIA E SEGURANÇA ALIMENTAR, 1., 2004, Brasília/DF. Anais... Brasília: 20-23 out., 2004. p. 117-129.

Recebido em: 27-12-2011.

Aprovado em: 27-01-2012. 